\title{
Construcción de la feminidad normativa y sujeto político
}

\author{
Sara MATEOS SILLERO \\ mateos.sara@gmail.com
}

Recibido: 01.02.2013

Aceptado: 15.11.2013

\begin{abstract}
RESUMEN
En las sociedades legalmente igualitarias siguen existiendo situaciones de desigualdad entre mujeres y hombres. Este análisis plantea que está relacionado con que siguen operando en el imaginario social las categorías bajo las que se construye la feminidad normativa. Un modelo de feminidad obligatoria que supondría la limitación de las actitudes y aptitudes de las mujeres a aquello que se desprende de la maternidad y la supuesta esencia femenina, ligada a ella. Sitúa el Estado y la religión como dos de las instituciones principales que producen y reproducen la feminidad normativa. El texto analiza su construcción a través del pensamiento de Rousseau, como uno de los "padres" del Estado moderno; y de la doctrina vaticana. La división sexual del trabajo va de la mano de esta feminidad normativa, que interviene incluso en cómo entendemos el amor. Tiene implicaciones en el ejercicio de la ciudadanía y el acceso a los recursos. Para finalizar, se abordan los aspectos que deben ser considerados para configurar un sujeto político (feminista) capaz de hacer frente a esta situación.
\end{abstract}

Palabras clave: Feminidad normativa, Estado, Religión, Sujeto político, Maternidad.

\section{Construction of femininity regulations and political subject}

\begin{abstract}
Understanding the current existence of gender inequalities as a citizenship deficit, this analysis links that deficit with the categories that are still functioning in the social imaginery and that build up the normative femininity. That femininity is indeed a compulsory model that reduces the attitudes and capabilities of women to all that is related to motherhood and the purported female essence thereof. The text analizes the construction of that model through the thinking of Rousseau, as one of the "fathers" of modern state, as well as through the doctrine emerging from Vatican. The sexual divison of labour is also closely connected to that normative femininity, shaping even the way we understand love, the way we exercise our citicenzhip and the unequal access to resources. We end up by addressing the aspects that should be considered to configure a (feminist) political subject capable to face up to this situation.
\end{abstract}

Keywords: Normative femininity, State, Religion, Political Subject, Motherhood. 


\section{PODER, PATRIARCADO Y NATURALEZA}

El poder constituye un concepto central en la Ciencia Política. Si bien se aborda de diversas formas, la referencia más frecuente ha sido la de Max Weber: el poder consiste en la probabilidad de imponer la propia voluntad, dentro de una relación social, aun contra toda resistencia y cualquiera que sea el fundamento de esa probabilidad.

Como marco teórico de esta investigación, hay que señalar que este análisis pone el acento en la relación social, abordando el poder como relación. Y entendiendo además las relaciones entre los géneros como relaciones de poder. Así, el poder es "una situación estratégica que surge con cada relación social, en la medida en que esa relación presente una desigualdad de fuerzas. Por ello, el poder se está produciendo a cada instante y en todos los puntos del entramado social donde se establecen relaciones" (Martín-Baró, 1989:102). No puede reducirse a ámbitos concretos, sino que se debe tener en cuenta en "la configuración de la vida cotidiana, en los mecanismos de las rutinas" (Martín-Baró, 1989:92). Tampoco puede entenderse como poder-coacción. Es el consentimiento el interés principal en este análisis. El poder produce y reproduce el sistema simbólico bajo el que los sujetos construyen sus percepciones. Actúa a través de las normas sociales, de las pautas de comportamiento, de los roles, de los modelos, de los ideales y valores, en definitiva, de la construcción de la cultura. Se aprende mediante la socialización y permite formar parte de un sistema social o una sociedad concreta. Nos socializamos mediante la interiorización de significados compartidos en la comunidad/sociedad/cultura en la que nacemos. Todo el engranaje que se construye en torno a esa comunidad definirá el comportamiento que deben tener los individuos que la componen. De este modo, la sociedad premiará (reconocimiento, premio...) o castigará (por medio de sanciones legales, sociales, etc.) los comportamientos para modular las conductas. En este proceso es necesario destacar los sistemas simbólicos ya que su efecto de dominación no se produce en la parte racional de nuestros procesos de pensamiento, sino en las categorías de esos procesos. En cómo está configurado el esquema de percepción. Hacen posible el consenso sobre el sentido del mundo social (Bourdieu, 2000a).

En la construcción de esta cosmovisión o esquema de percepción del mundo es el sistema sexo-género, o patriarcado, el marco referencial a cuestionar. Según Victoria Sau (2006), el patriarcado es una estructura no escrita pero inscrita en la sociedad.

"El Patriarcado está compuesto de usos, costumbres, tradiciones, normas familiares y hábitos sociales. Para perpetuarlos, para que siguieran vigentes una generación tras otra, hizo falta algo más que la Ley, ley del Padre, fueron necesarios educadores, filósofos, pedagogos, médicos, religiosos, juristas y políticos. Toda una red de servidores del nuevo sistema, a veces incluso con la complicidad de algunas mujeres". 
Sin embargo, el patriarcado y la división sexual del mundo se presentan como naturales. La naturalización del poder es sin duda su herramienta más eficaz. No sólo lo justifica, sino que dificulta su cuestionamiento y, por ende, la posibilidad de acción humana. Para entender este proceso Bourdieu (2000a: 12) explica que se transforma la historia en naturaleza, y la arbitrariedad cultural en natural. Así, "un prolongado trabajo colectivo de socialización de lo biológico y biologización de lo social se conjugan para invertir la relación entre las causas y los efectos". Con respecto a la división sexual y asimétrica de la sociedad, se trataría pues de "hacer aparecer una construcción social naturalizada (los "géneros" en cuanto que hábitos sexuados) como el fundamento natural de la división arbitraria que está en el principio tanto de la realidad como de la representación de la realidad" (Bourdieu, 2000a: 14).

Cómo señala Valcárcel (1991), desde un cínico revestimiento laico-racional, el naturalismo transforma a las mujeres en hembras, atribuyendo a dicha categoría una esencia precívica. La superioridad de los varones es natural y por tanto, no responde a estructuras ideológicas excluyentes de carácter ético o político sino a un principio rector de la naturaleza.

"La preeminencia universalmente reconocida a los hombres se afirma en la objetividad de las estructuras sociales y de las actividades productivas y reproductivas, y se basa en una división sexual del trabajo ... que confiere al hombre la mejor parte, así como en los esquemas inmanentes a todos los hábitos" (Bourdieu, 2000a:49).

Así, al incidir en los esquemas que componen la estructura de las percepciones, la superioridad de los varones queda sumergida en una supuesta objetividad universalmente compartida que se aplica a la construcción del conocimiento. Esta posición privilegiada no sólo queda naturalizada, además, se presenta como universal. Se denomina humano a lo que en realidad se ha establecido bajo cánones androcéntricos. Las mujeres, que forman parte del proceso, aplican "unos esquemas mentales que son el producto de la asimilación de estas relaciones de poder y que se explican en las oposiciones fundadoras del orden simbólico" (Bourdieu, 2000a:49). Esto dificulta a las propias mujeres la identificación de la situación de desventaja en la que estructuralmente se ha establecido la categoría mujer.

Para Jónnasdóttir (1993: 319) "la reproducción de la autoridad masculina está lejos de ser meramente una cuestión de ideas subjetivas que habitan con mayor o menor intensidad en las cabezas de individuos aislados. También debe entenderse como un proceso objetivo en marcha, sean conscientes o no los individuos de lo que está pasando". En este proceso, "los dominados aplican a las relaciones de dominación unas categorías construidas desde el punto de vista de los dominadores, haciéndolas aparecer de ese modo como naturales". Esto incide en la obediencia voluntaria, "ya 
que permite que vea la persona su propio comportamiento como algo que sirve para una finalidad deseable" (Bourdieu, 2000a:154).

Incidimos por tanto en que frente a la dimensión coactiva del poder y a la utilización de la violencia, el interés principal de esta investigación se deposita en el consentimiento, en la incitación.

"La violencia física es una estrategia de control efectiva pero inviable a largo plazo... Una estrategia normativa más sutil y efectiva es aquella que determina y moldea las estructuras perceptivas y conductuales de los sujetos sociales para dotarles de una identidad que no cuestione el entramado cultural sobre el que se erige el discurso patriarcal" (Beteta, 2009:164).

La feminidad normativa forma parte del esquema de percepciones, de un orden simbólico totalmente interiorizado que implica que las categorías asociadas a la mujer y a las mujeres construidas bajo criterios patriarcales, se asuman sin embargo, como naturales y objetivas, siendo las mujeres parte del proceso de reproducción. Esto supone cierta dificultad para desprenderse de ella (la feminidad normativa), incluso cuando se persiguen objetivos de igualdad.

Como última pieza de este engranaje del funcionamiento del poder como relación, hay que señalar las consideraciones de Celia Amorós $(1997,2005)$. Parte de que "el patriarcado, aunque como forma de dominación tiene efectos sistemáticos, no constituye una unidad ontológica. Desde este punto de vista podríamos asumir la definición de Heidi Hartmann del patriarcado "como un conjunto de relaciones sociales entre los hombres que tienen una base material y que, sin bien son jerárquicas, establecen o crean una interdependencia y solidaridad entre los hombres que les permite dominar a las mujeres". Se trata pues de un conjunto de "pactos", y, así, la noción de patriarcado podría resolverse en la de conjunto de pactos patriarcales" (Amorós, 2005: 113,114). Enfaticemos que el poder no se tiene, se ejerce: no es una esencia o una sustancia, es una red de relaciones. El poder nunca es de los individuos, sino de los grupos (Amorós, 1997,2005). Grupos que poseen auctoritas y que regulan el acceso a las instancias donde esta auctoritas se produce y reproduce (con la capitalización de la producción simbólica). Desde esta perspectiva, el patriarcado es un "sistema de pactos interclasistas entre los varones".

\section{INSTITUCIONES REGULADORAS. ESTADO E IGLESIA}

Como plantea Bourdieu, una historia de las mujeres "está obligada...a dejar un espacio, ...el más importante, a la historia de los agentes y de las instituciones que concurren permanentemente a asegurar esas permanencias" (Martín-Baró,1989:105). Para Bourdieu (2000a) las estructuras de dominación resultan de un trabajo 
continuado, y por tanto histórico, de reproducción. En este proceso contribuyen tanto agentes singulares como instituciones, aludiendo fundamentalmente a la Familia, la Iglesia, el Estado y la Escuela. A lo que cabría añadir la Ciencia como discurso validante más contundente. Por lo que "si queremos explicar ... las diferencias sociales y políticas importantes entre mujeres y hombres, tenemos que poner de manifiesto sus fuentes generadoras, las fuentes de poder que las producen" (Jónnasdóttir 1994:278).

De las instituciones mencionadas, este análisis se aproxima a dos de ellas, Estado e Iglesia, por entender que son las fuentes generadoras de los preceptos filosóficos-en este caso ilustrados- bajo las que se establecerían las otras ${ }^{1}$.

\section{a. El Estado moderno como patriarcado público.}

La aparición de los Estados modernos se explica con la Teoría del Contrato Social, cuyo mayor exponente es Rousseau. Pero esta ficción, como analiza Pateman (1995), va a suponer además el establecimiento de otro pacto subjectionis, el "contrato sexual", que transforma la "diferencia sexual" en "diferencia política". El sexo determinará el posterior desarrollo de las categorías socio-políticas derivadas de esta ficción contractual, base de nuestros sistemas políticos (occidentales) actuales, quedando los Estados modernos "inscritos bajo los principios fundamentales de visión androcéntrica (Bourdieu, 2000a).

El argumento ontológico que permite legitimar esta división sexual es la negación de la individualidad a las mujeres, concebidas como seres más próximos a la naturaleza, debido in fine a su capacidad reproductora. No serán sujetos válidos para firmar el pacto, sólo podrán consentir un contrato a través del cual se introducirán en la sociedad civil, el matrimonio. A la negación de la individualidad acompaña el proceso de heterodesignación (Celia Amorós, 1997: 383) que hace referencia a la construcción identitaria común que el patriarcado, como sistema de dominación, proyecta sobre todas las mujeres y que impide su investidura como sujetos individualizados ${ }^{2}$, los iguales frente a las idénticas. El resultado de esta ontología "era que la mujer, desde el punto de vista filosófico y judicial, esto es, en la teoría y en la práctica, era excluida del nuevo concepto santificado de Hombre [individuo], excluida de la Humanidad" (Jónnasdóttir, 1993: 265).

\footnotetext{
${ }^{1}$ Me estoy refiriendo al mundo occidental, pero resulta relevante tener en cuenta que en lo concerniente a la feminidad normativa, las categorías bajo las que se basa su construcción son las mismas en todas las partes del mundo con influencia de las denominadas religiones del Libro, los tres monoteísmos: Judaísmo, Cristianismo e Islam, que abarca buena parte del planeta.

2 De esta forma "las mujeres comparten una situación común: los varones les imponen que no asuman su existencia in recto como sujetos, sino que se identifiquen con la proyección que en ellas hacen de sus deseos como si fueran el Otro, la conciencia inesencial".
} 
Con el Contrato sexual se crean además dos espacios diferenciados adecuados cada uno de ellos a las características propias de cada sexo: el público pertenecerá a los varones y el privado a las mujeres. La negación de las mujeres en el ámbito público de toda índole, no sólo de espacios, también de saberes, las relega a un status inferior como seres sociales, puesto que en la esencia misma de lo social está lo público, y éste es un espacio compartido entre iguales y generador de ciudadanía. Pero la exclusión de las mujeres del Contrato social significa no sólo mantenerlas al margen (o en el margen) de la ciudadanía. A través del análisis del pensamiento de Rousseau se extrae, como apunta Rosa Cobo (1992:261), que en la propia génesis del Contrato, y en su mantenimiento, está la necesidad de esa posición relegada de las mujeres para el sostenimiento de las modernas democracias, convirtiéndolas así en patriarcales.

\section{b. Religión y orden social.}

Cuando la religión deja de dotar de legitimidad directa y explícita al poder, ocurre un proceso cuyo desmantelamiento es aún más complejo, a la Biblia se acude para alimentar elementos polémicos en torno a definiciones y principios morales de los que los sujetos son o pueden llegar a ser. Se llega así a la orientación de conductas y de conciencias, discerniendo el buen del mal comportamiento. Supone, en términos weberianos, la "racionalización" ética de la conducta vital. Cabe destacar por ello el papel de la religión como conjunto normativo, en la conciencia y la cultura política de la sociedad -compuesta de personas tanto creyentes como no creyentes-.

"La competencia por el poder religioso debe su especificidad (por medio de la competencia que se establece en el campo político por ejemplo) al hecho que tiene como apuesta el monopolio del ejercicio legítimo del poder de modificar durablemente y profundamente la práctica y la visión del mundo de los laicos imponiéndoles e inculcándoles un habitus religioso particular. i. e. una disposición durable, generalizada y transferible para actuar y pensar conforme a los principios de una visión (quasi) sistemática del mundo y de la existencia" (Bourdieau, 2000c: 52).

Resalta la imbricación de la moral -derivada más o menos secularizada de los valores y las interpretaciones judeo-cristianas- con los principios que rigen el orden civil, sus modelos de comportamiento, el papel por tanto, de la religión como conjunto normativo, en la conciencia y la cultura política de la sociedad. Puede verse mediante el debate, por ejemplo, del matrimonio entre personas del mismo sexo, donde siendo el matrimonio un contrato en el código civil, sin embargo se trata como un sacramento; o la débil frontera entre la concepción de pecado y de delito, 
resultando la más obvia la relacionada con los derechos sexuales y reproductivos de las mujeres ${ }^{3}$.

En este análisis, nos aproximamos a la religión desde la doctrina de la Iglesia Católica", ya que "la relación establecida entre la mujer, el sexo y el pecado constituye el modelo primordial de todo el pensamiento occidental posterior" (Millet, 2010: 118).

\section{c. Discurso vaticano sobre la mujer.}

La situación de las mujeres ha cambiado, los nuevos derechos conseguidos vislumbran que el cambio se acelera y que el viejo sistema que se va convirtiendo legalmente en cuasi igualitario va a tener que buscar otros mecanismos para seguir manteniendo a las mujeres fuera de los círculos de poder. Así, el discurso vaticano sobre la mujer da un giro a partir del Concilio Vaticano II (1963-65). La Iglesia pasa del discurso explícito de la inferioridad al discurso del agrado y de la exaltación de las virtudes femeninas, denominadas por el Vaticano como el "genio de la mujer" o el "genio femenino". Con motivo del Año Mariano, en 1988, el papa Juan Pablo II promulga una Carta sobre la dignidad de la mujer Mulieris Dignitatem. En ella se exponen los grandes principios sobre la "cuestión femenina" y continúa la línea abierta en el Concilio Vaticano II. En la IV Conferencia Mundial sobre la Mujer, celebrada en Pekín en 1995, el Papa Juan Pablo II expone la postura oficial del Vaticano en la Conferencia a través de la Carta a las Mujeres, documento que "resulta ser ... una confirmación del esfuerzo de la Iglesia para salvaguardar la dignidad y los derechos de todas las mujeres..." (FIDES, 2008:6). Es preciso señalar que la dignidad de las mujeres, como veremos, está ligada a su esencia femenina.

En 2004, la Congregación Para la Doctrina de la Fe del Vaticano difunde una misiva a sus obispos, un documento de carácter doctrinal titulado Carta a los Obispos de la Iglesia Católica sobre la Colaboración del Hombre y la Mujer en la Iglesia y el Mundo. Una clara respuesta al avance del feminismo como teoría emancipatoria, que insiste en la sujeción de la mujer a su naturaleza propia y específica de una forma todavía más explícita. Es, dicho de otra manera, una alabanza a la diferencia. "La Iglesia se siente ahora interpelada por algunas corrientes de pensamiento, cuyas tesis frecuentemente no coinciden con la finalidad genuina de la promoción de la mujer" (§1). Reiteran su oposición al concepto de género, como ya habían expresado en

\footnotetext{
${ }^{3}$ Que cabe recordar son considerados Derechos Humanos desde la Conferencia de NNUU sobre Población y Desarrollo de 1994 en El Cairo.

${ }^{4}$ No se entra en cuestiones de exégesis bíblica, ya que nos interesa lo que dice la doctrina vaticana, no lo que podría llegar a decir.
} 
Pekín, por el constructivismo que implica ya que para la iglesia las diferencias entre mujeres y hombres, no sólo son naturales, sino que son complementarias.

La Iglesia, reconfigura su modelo de feminidad compartiendo simbióticamente los criterios filosóficos ilustrados, reafirmándolos y con la especial característica de dotarlos de la legitimidad religiosa que le confiere la fe.

\section{CONSTRUCCIÓN DE LA FEMINIDAD NORMATIVA.}

Podemos establecer siete categorías en la conformación de la feminidad normativa que se encuentran en los discursos, tanto de Rousseau, como máximo exponente de la configuración del estado moderno (patriarcal); como de la doctrina de la Iglesia Católica: a) que la igualdad genera conflicto; b) la negación de la individualidad femenina y la naturalización de las diferencias; c) el esencialismo femenino vinculado a la maternidad; d) la teoría de la complementariedad y la Familia; e) la asignación diferenciada de espacios; f) un único modelo de feminidad encarnado en Sofía y María; y por último, más que una categoría, g) una estrategia de poder en la reproducción de la feminidad normativa.

\section{a. La igualdad genera conflicto.}

Para la Iglesia las diferencias entre los sexos no sólo son naturales, sino que son complementarias, por lo que anular esas diferencias con la nivelación ${ }^{5}$, sólo podrá traer desorden y confusión. Juan Pablo II, en su Carta a las Mujeres, expresa que la nivelación, pretender anular las diferencias basándose en "una confusión que encuentra sus raíces en la idea de que cada uno puede ser lo que quiera, sin considerar y respetar sus principios biológicos" sólo arroja confusión sobre el sentido de la familia, la sexualidad, la maternidad...

También Rousseau (1997:565) advertía de lo insostenible para la sociedad de la igualdad entre sexos: "Si la mujer pudiera elevarse tan bien como el hombre a los principios, y el hombre tuviera tan bien como ella el espíritu de los detalles, siempre independientes uno de otro viviría en discordia eterna y su sociedad no podría subsistir".

La idea de la complementariedad prima sobre la de igualdad o nivelación. Se enfatiza la necesidad de la diferencia ya que si no, advirtamos la gravedad del asunto, el orden social podría romperse.

\footnotetext{
${ }^{5}$ Cabe señalar como muestra de la estrategia discursiva que no se refieren a la igualdad de forma explícita, sino a la nivelación.
} 


\section{b. Negación de la individualidad y naturalización de las diferencias.}

La aparición del individuo como tal en la modernidad supone un cambio radical en la visión del mundo, un aumento de perspectivas. La modernidad supone la revolución individualista, "por la que, por primera vez en la historia, el ser individual, igual a cualquier otro, es percibido y se percibe como fin último, se concibe aisladamente y conquista el derecho a la libre disposición de uno mismo" (Lipovetsky, 1987:93). Hemos mencionado cómo los estados modernos nacen mediante la ficción del Contrato Social que niega la individualidad a las mujeres. El hombre es un individuo, la mujer, por el contrario, no tiene existencia fuera de su genérico. Como Celia Amorós (2005:97) ha analizado, las mujeres, "serán tratadas práctica y simbólicamente como las idénticas, indiscernibles - pues no son individuosen un bloque ontológico compacto" (igualdad de los varones frente a identidad de las mujeres).

Para este proceso se siguen los siguientes pasos teóricos ${ }^{6}$ :

- Naturalizar las diferencias. Definir una naturaleza femenina, distinta y complementaria de la masculina.

- $\quad$ Proceder a una interpretación de su biología acorde con las funciones sociales que debe desempeñar en el ámbito que le ha asignado, naturalizando y haciendo necesarias las diferencias (complementariedad).

- Atribuir a la mujer un tipo de razón diferente a la masculina (lo inmediato frente a lo abstracto).

- Otorgarle un objeto educativo preciso (en el amor y la virtud)

La exclusión de las mujeres de la categoría central de "individuo" ha tenido expresión legal y social en la discriminación en los sistemas legales que sustentan las democracias modernas (aunque se vaya corrigiendo en su plano formal), y por tanto, en el ejercicio de la ciudadanía.

\section{c. Esencialismo femenino. Un único destino, la maternidad.}

La diferencia sexual no queda en el dato biológico, se traduce en toda una serie de añadidos que tienen que ver con los valores, las inquietudes, las aspiraciones... conforman una esencia bien definida otorgada por el sexo ${ }^{7}$.

\footnotetext{
${ }^{6}$ Tomando las claves de Rosa Cobo (1995:232) respecto a los pasos teóricos en la construcción de la feminidad o del sujeto mujer en Rousseau que se aplican de igual modo al sustrato ideológico vaticano.
} 
... hay que hacer notar la importancia y el sentido de la diferencia de los sexos como realidad inscrita profundamente en el hombre y la mujer. "La sexualidad caracteriza al hombre y a la mujer no sólo en el plano físico, sino también en el psicológico y espiritual con su impronta consiguiente en todas sus manifestaciones». Ésta no puede ser reducida a un puro e insignificante dato biológico, sino que «es un elemento básico de la personalidad; un modo propio de ser, de manifestarse, de comunicarse con los otros, de sentir, expresar y vivir el amor humano» (Carta a los Obispos §8).

"Lo que se llama «femineidad» es más que un simple atributo del sexo femenino. La palabra designa efectivamente la capacidad fundamentalmente humana de vivir para el otro y gracias al otro" (Carta a los Obispos... §14). En la esencia femenina está no sólo la capacidad de entrega, sino la voluntad de entregarse al otro. El concepto de realización personal por tanto se vincula a este fin, que no sólo cumplirá una función social deseable, también repercutirá en su felicidad personal al responder a su naturaleza de cuidadora.

"Entre los valores fundamentales que están vinculados a la vida concreta de la mujer se halla lo que se ha dado en llamar la «capacidad de acogida del otro». No obstante el hecho de que cierto discurso feminista reivindique las exigencias «para sí misma», la mujer conserva la profunda intuición de que lo mejor de su vida está hecho de actividades orientadas al despertar del otro, a su crecimiento y a su protección" (Carta a los obispos $§ 13)$.

Esta intuición ${ }^{8}$ implica el desarrollo del "sentido por lo concreto" (Carta a los obispos... §13). Como Rousseau (1997:565) cada sexo posee una razón específica, con las consecuencias que acarrea en cuanto al tipo de tipo de tareas que pueden desempeñar virtuosamente ${ }^{9}$.

La intuición femenina proviene de la maternidad potencial, sea ejercida o no. Para la Iglesia, "esta intuición está unida a su capacidad física de dar la vida. Sea o no puesta en acto, esta capacidad es una realidad que estructura profundamente la personalidad femenina (Carta a los obispos §13). Rousseau (1997:232) establece que

\footnotetext{
${ }^{7}$ Es importante señalar que la esencia minuciosamente descrita es únicamente femenina con el genio femenino. No existe ningún genio masculino.

${ }^{8}$ La Real Academia Española de la Lengua define como la intuición como la "facultad de comprender las cosas instantáneamente, sin necesidad de razonamiento". Que las mujeres posean la intuición de la entrega al otro las sitúa en un campo más próximo al estado de naturaleza que al del raciocinio.

${ }^{9} \mathrm{La}$ de la mujer se relaciona con lo concreto, lo cotidiano -los medios-, la masculina con lo abstracto -los fines-. "La razón de las mujeres es una razón práctica que les hace encontrar con mucha habilidad los medios para llegar a un fin conocido, pero que no les hace encontrar ese fin".
} 
"la maternidad, más allá de ser un componente decisivo en la naturaleza de la mujer, puede decirse que constituye su destino": "Las mujeres decís, no siempre tienen hijos. Cierto, pero su destino es tenerlos" (1997:540). La maternidad liga a las mujeres ineludiblemente a la naturaleza, en sentido ontológico, les hace permanecer sin excepción (por esencia) más cerca de ella. Se constituye así en la característica fundamental del orden simbólico femenino.

Vincular la capacidad reproductora con todo un repertorio de cualidades relacionadas con el cuidado y la atención hacia los demás es recurrente en todo el pensamiento anti-igualitario. Del hecho biológico de la capacidad de engendrar se desprende que las mujeres estás más próximas a la naturaleza y son, esencialmente, biológicamente, más dulces, cariñosas, sensibles, bondadosas, etc. que los varones. La consecuencia de este esencialismo es que se configura el sentido de la vida de las mujeres ${ }^{10}$ en una única opción universal para el sexo femenino por el hecho de serlo, negando ontológicamente a la mujer como individuo, como sujeto. Se trata de la Otredad Absoluta que define Amelia Valcárcel (1997: 27).

\section{d. Teoría de la complementariedad y Familia.}

Frente a la pretensión de nivelación que provoca discordia, la Iglesia habla de "colaboración activa entre el hombre y la mujer. Precisamente en el reconocimiento de la diferencia misma" (Carta a los Obispos §4), ya que se basa en el principio ontológico de la complementariedad de los sexos, "La igual dignidad de las personas se realiza como complementariedad física, psicológica y ontológica, dando lugar a una armónica «unidualidad» relacional. (Carta a los Obispos §8). Esta complementariedad, a su vez, se basa en el principio de ayuda.

« No es bueno que el hombre esté solo. Voy a hacerle una ayuda adecuada » (Gn 2, 18). En la creación de la mujer está inscrito, pues, desde el inicio el principio de la ayuda: ayuda —mírese bien - no unilateral, sino recíproca. La mujer es el complemento del hombre, como el hombre es el complemento de la mujer: mujer y hombre son entre sí complementarios. La femineidad realiza lo « humano » tanto como

\footnotetext{
${ }^{10}$ Como resume agudamente Badinter, "No es un azar que las primeras mujeres que escucharon los discursos masculinos sobre la maternidad fueran burguesas. Ni pobre, ni particularmente rica o brillante, la mujer de las clases medias vio en esta nueva función la oportunidad de una promoción y una emancipación que la aristócrata no buscaba... se convertía en el fundamento central de la familia... a madre es consagrada como "soberana doméstica"... La maternidad se transforma en una función gratificante porque ahora está cargada de ideal. El modo en que se habla de esta "noble función", con un vocabulario sacado de la religión, señala que a la función de madre se asocia un nuevo aspecto místico. La madre es comparada de buena gana con nunca santa y la gente se habitúa a pensar que una buena madre es "una santa". La patrona natural de esta nueva madre es la Virgen María cuya vida testimonia la dedicación a su hijo". E. Badinter en Valcárcel (2001: 13).
} 
la masculinidad, pero con una modulación diversa y complementaria (Carta del Papa Juan Pablo II a las Mujeres §7).

Puede que la ayuda sea recíproca en la teoría, pero en el desarrollo del discurso este principio sólo está normado para la mujer, quien posee por naturaleza la capacidad de entrega al otro otorgada por don de la maternidad.

“... la mujer y el hombre no reflejan una igualdad estática y uniforme, y ni siquiera una diferencia abismal e inexorablemente conflictiva: su relación más natural (...) es la "unidad de los dos" o sea una "unidualidad" relacional, que permite a cada uno sentir la relación interpersonal y recíproca como un don enriquecedor y responsabilizante.

...Sólo gracias a la dualidad de lo "masculino" y de lo "femenino" lo "humano" se realiza plenamente. (Carta del Papa Juan Pablo II a las Mujeres §7).

Esta complementariedad y unidad relacional tiene su fundamento y máxima expresión en la Familia, llevada a cabo por medio del matrimonio.

La importancia que para la Iglesia tiene la Familia se muestra en la práctica totalidad de sus documentos, donde la salvaguarda de la misma suele ser el fin último de otros elencos normativos. De hecho el Vaticano cuenta con el Pontificio Consejo para la Familia ${ }^{11}$.

Idéntica posición reproduce Rousseau: Sólo los dos sexos juntos y unidos a través del matrimonio adquieren la perfección moral y se convierten en otra unidad, "cada miembro del matrimonio aporta su naturaleza específica y las obligaciones morales y materiales que se derivan de su naturaleza" (Cobo, 1995:242). En Rousseau, "al igual que conceptualiza las dos naturalezas, la femenina y la masculina, como complementarias, la nueva definición del ideal del mujer y de familia responde a ese interés" (Cobo, 1995:228). Si entre los dos sexos, en lugar de complementariedad hubiese igualdad, se producirían conflictos que pondrían en cuestión la supervivencia del esquema doméstico y político patriarcal.

En Rousseau, que puede considerarse como el creador del ideal moderno de familia patriarcal, la Familia es la institución que, por una parte, vertebra el ámbito privado y en este sentido, se convierte no sólo en base, sustento y soporte del ámbito público, sino también en referente de unidad social; y por otra, es el espacio capaz de controlar, neutralizar $\mathrm{y}$, en algunos casos, transformar el siempre potencial y

${ }^{11}$ Instituido por Juan Pablo II con el Motu Proprio Familia a Deo Instituta en 1981, sustituyó al Comité para la Familia, creado por Pablo VI en 1973. Su trabajo alcanza a la promoción de la familia desde un punto de vista cristiano. 
peligroso mal que de una forma subrepticia se encuentra en la naturaleza femenina (Cobo, 1995:241).

\section{e. El patriarcado es poder de asignar espacios ${ }^{12}$. La división sexual del trabajo.}

Con el avance de las democracias modernas las mujeres acceden al espacio público. Al filósofo ginebrino no se le planteó esta disyuntiva pero dada la simbiosis discursiva entre los preceptos ilustrados patriarcales y la doctrina vaticana contemporánea, la postura de la Iglesia Católica servirá de muestra argumental para justificar que, aunque las mujeres estén presentes en el ámbito público y cada vez en más número, la ubicación natural de las mujeres, por sus cualidades, está en lo privado y no deben descuidar su principal función de cuidadora. A través de una oda a sus cualidades, a su genio femenino, se establecen no sólo los límites de actividad pública de las mujeres, sino los ámbitos donde mejor pudieran desarrollar su labor (esto es, todo lo relacionado con el campo de los cuidados).

"En tal perspectiva se entiende el papel insustituible de la mujer en los diversos aspectos de la vida familiar y social que implican las relaciones humanas y el cuidado del otro. Aquí se manifiesta con claridad lo que el Santo Padre ha llamado el genio de la mujer. (Carta a los Obispos §13)

Las bondades genuinamente femeninas, adheridas al sexo biológico mujer, deben estar presentes también en otros aspectos de la vida social y pública. "Esto implica, además, que las mujeres estén presentes en el mundo del trabajo y de la organización social, y que tengan acceso a puestos de responsabilidad que les ofrezcan la posibilidad de inspirar las políticas de las naciones y de promover soluciones innovadoras para los problemas económicos y sociales". Al hecho del reconocimiento de que las mujeres deben estar presentes en todos los ámbitos políticos, económicos y sociales no hay nada que objetar, es un paso adelante ${ }^{13}$. Pero al motivo al que aluden para ello sí, es decir, al de que la mujer tiene que estar presente para irradiar ese genio femenino que les otorga la potencialidad de la maternidad.

Pero... ¿qué pasa con la familia si la mujer trabaja fuera? En este asunto tampoco caben dudas: "no se puede olvidar que la combinación de las dos actividades - la familia y el trabajo - asume, en el caso de la mujer, características diferentes que en el del hombre. Se plantea por tanto el problema de armonizar la legislación y la organización del trabajo con las exigencias de la misión de la mujer dentro de la

${ }^{12}$ MOLINA, Cristina, Dialéctica feminista de la Ilustración, en AMORÓS, Celia (2005), La gran diferencia..., p. 98.

${ }^{13}$ Aunque muestren total incoherencia manteniendo su estructura patriarcal e inamovible. 
familia". Como ha escrito Juan Pablo II en su Carta a las Mujeres, «será un honor para la sociedad hacer posible a la madre — sin obstaculizar su libertad, sin discriminación psicológica o práctica, sin dejarle en inferioridad ante sus compañeras - dedicarse al cuidado y a la educación de los hijos, según las necesidades diferenciadas de la edad»»"(§13). La Doctrina Social es clara:

"295. El reconocimiento y la tutela de los derechos de las mujeres en este ámbito dependen, en general, de la organización del trabajo, que debe tener en cuenta la dignidad y la vocación de la mujer, cuya « verdadera promoción... exige que el trabajo se estructure de manera que no deba pagar su promoción con el abandono del carácter específico propio y en perjuicio de la familia, en la que como madre tiene un papel insustituible »

No se trata de conseguir que las mujeres no sean discriminadas en lo laboral, sino de que las madres no sean discriminadas en lo laboral. No se trata de no discriminar para que las mujeres desarrollen plenamente sus capacidades en el ámbito profesional, sino para que desarrollen plenamente la maternidad, en su papel insustituible en la Familia. Se trata, por tanto, de que la actividad pública garantice los derechos de las madres, no de los individuos.

Es necesario enfatizar que "la excelencia de las virtudes femeninas para el cuidado se convirtió en un poderoso freno, simbólico y material, para la participación de las mujeres en el espacio público" (Álvarez-Conde, 2009:300).

\section{f. Sofía y María. Un modelo de feminidad: la vocación al amor.}

Dijo luego el Señor Dios: "No es bueno que el hombre esté solo. Voy a hacerle una ayuda adecuada" (Génesis 2:18)

No es bueno que el hombre esté solo, Emilio es hombre; le hemos prometido una compañera, hay que dársela. Esa compañera es Sofía. (Rousseau, Emilio o de la Educación p. 533)

Sofía y María representan el modelo de mujer ideal, la feminidad normativa. María es la esposa de Dios y la madre de los creyentes, del mismo modo que Sofía es la esposa del ciudadano y madre del mismo. La referencia moral y portadora de valores que brotan de su esencia femenina -ligada a la maternidad- que debe ser protectora de y protegida por la Familia. Las mujeres son la base de la familia, quienes transmiten los valores más humanos, la reserva de la moral para la sociedad... pueden expandir sus bondades femeninas en ámbitos públicos, sin descuidar, por supuesto, su principal misión y vocación, otorgada por el don de la maternidad. Su poder real está en lo privado. "La Iglesia ve en María la máxima expresión del "genio femenino" y encuentra en ella una fuente de continua inspiración” (Carta del Papa Juan Pablo II a las Mujeres, §10). Enseña a la 
humanidad..."con sus disposiciones de escucha, acogida, humildad, fidelidad, alabanza y espera (...) [que] Aun tratándose de actitudes que tendrían que ser típicas de cada bautizado, de hecho, es característico de la mujer vivirlas con particular intensidad y naturalidad" (§12). Se trata del "genio femenino".

Rousseau, en su Emilio o de la Educación, tratado sobre la educación que debe recibir el ciudadano ideal, Emilio, dedica el Libro V a cómo debe ser la esposa y compañera ideal de éste, Sofía, y cuál debe ser el papel de ambos en el espacio privado. "Una mujer casta y modesta, pronta a tener en cuenta las opiniones de los demás y dedicada por completo a su familia y a su casa es el prototipo ideal de la mujer natural" (Cobo, 1993: 315).

\section{Como expresa Nancy Armstrong (1991:9):}

"El nuevo modelo de mujer -la mujer doméstica "reina del hogar"- no constituyó simplemente un modelo de feminidad, sino que acabó convirtiéndose en el modelo de subjetividad para el individuo moderno, producto de la cultura burguesa en formación, basada sobre unos valores que implicaban el desplazamiento de lo socio-político en favor de las relaciones aparentemente universales y subjetivas (emocionales y sexuales) entre hombres y mujeres individuales".

\section{g. $\quad$ Estrategias de poder.}

Sin embargo, a pesar de esta supuesta predisposición natural de las mujeres al amor, es necesario "educarlas" en sus funciones. Lo que desvela cierta incoherencia argumental. Rousseau (1997:207 y ss) advierte que "Emilio ... no es un libro para el pueblo, sino un nuevo sistema de educación dirigido a los sabios". En su capítulo V, Sofia, "no sólo se narran las nuevas cualidades de naturaleza femenina, sino también las técnicas de regulación de sus deseos". ¿Y cuáles son esas técnicas? "La esposa y la madre rousseauniana no deben estar sujetas al varón por la fuerza, sino por el consentimiento" (Cobo, 1995:231). Elemento que protagoniza la perspectiva del poder desde la que se aborda este a análisis, frente a la coacción. Este "consentimiento" se consigue a través de las nociones de amor y de virtud. "La esposa obedece al marido y cuida a los hijos porque les ama y porque así se convierte en una mujer virtuosa" (Cobo, 1995:231). Cumplir su misión les hará ser valoradas en la sociedad, que debe reconocer sus virtudes. Rousseau (1997:459) afirma: "Dad sin escrúpulo una educación de mujer a las mujeres, haced que amen los cuidados de su sexo, que tengan modestia, que sepan velar por su hogar y ocuparse de su casa; el traje de gala caerá por sí mismo, y ellas no se arreglarán sino con mejor gusto" ${ }^{14}$.

${ }^{14}$ La justificación ideológica es vital cuando se trata de conseguir una obediencia voluntaria, ya que permite que vea la persona su propio comportamiento como algo que sirve para una finalidad deseable. 
Siguiendo la lógica de L. Kohlberg (Vander Zanden, 1995) en cuanto al rol de género adquirido durante la socialización, si eres varón o mujer y haces cosas de varón o mujer respectivamente, recibirás aprobación y por lo tanto sentirás gratificación. Por otro lado, del mismo modo que se compensa socialmente el buen comportamiento, se sanciona el que no es "correcto". Especialmente importante es el sentimiento de culpa, muy vinculado a la moral religiosa ${ }^{15}$. De este modo,

“...además de las sanciones sociales aún presentes en nuestras sociedades, que estigmatizan y castigan a las mujeres que rompen el estereotipo, nos encontramos con mecanismo psíquicos de sujeción (Butler), es decir, aquellos dispositivos de control que nos coartan cuando nos salimos de "lo bueno, lo deseable, lo aceptado", mecanismos que funcionan con efectos de miedo, culpa u otras emociones imposibilitantes y que restan agencia" (Alfaro, 2005:110).

Así, existe un choque argumental al conjugar lo que vendría dado por naturaleza y por ello es invariable, con una minuciosa labor de socialización que requiere la modulación de los deseos. Convertir y convencer no parecen dos cualidades muy asociadas a la naturaleza. "También la mujer, por su parte, tiene que dejarse convertir, y reconocer los valores singulares y de gran eficacia de amor por el otro del que su femineidad es portadora" (Carta a los Obispos §17)

Como se ha mencionado anteriormente, se ha pasado del discurso explícito de la inferioridad natural y de la mujer como portadora del mal, al discurso de la excelencia y del agrado. "Las mujeres son el regalo más bonito que Dios ha dado a los hombres" (1998, Mulieris dignitatem §1). Suele ser frecuente en este tipo de argumentos contraponer además las "virtudes" femeninas esencialmente buenas ("genio femenino"), a los "defectos" masculinos, se consigue así además de incrementar el valor simbólico de lo femenino normativo, fundamentar la complementariedad de los sexos, imprescindible para la supervivencia de la humanidad. "Se debe recibir el testimonio de la vida de las mujeres como revelación de valores, sin los cuales la humanidad se cerraría en la autosuficiencia, en los sueños de poder y en el drama de la violencia" (Carta a los Obispos §17). (Poder y

MARTÍN-BARÓ, Ignacio (1989), Sistema, grupo y poder. Es interesante en este punto recordar a Foucault (1998:10), "lo que define una relación de poder es que éste es un modo de acción que no opera directa o inmediatamente sobre los otros, sino que el poder actúa sobre las acciones de los otros: una acción sobre otra acción, en aquellas acciones existentes o en aquellas que puedan generarse en el presente y en el futuro".

${ }^{15}$ Como ha analizado, entre otras, Victoria Sendón, las culturas tienen una serie de argumentos legales y simbólicos para introducir la culpa en los individuos para que las sociedades injustas puedan seguir existiendo. 
violencia, son valores propiamente masculinos en esta visión dualista del mundo, de la diferencia sexual).

A modo de síntesis, y siguiendo el elucidario de Amelia Valcárcel (1997), la lógica de la construcción de la feminidad normativa es la siguiente: 1. Naturalización de las diferencias. Si el feminismo plantea la discriminación y la subordinación como una cuestión política -de relaciones asimétricas y jerárquicas de poder- la respuesta del poder interpelado es naturalizar esa diferencia: dotando a cada sexo de principios de acción y de excelencia particulares, o más bien, dotando a las mujeres de peculiares excelencias que las reconducirán a su lugar en el mundo. 2. No sólo somos diferentes, sino que somos complementarios. No es conveniente ni deseable que los sexos neutralicen sus características normativas, sino que las exageren. Ello es garantía de orden. No son iguales, sino complementarios. Así lo ha querido la naturaleza. 3. Estas diferencias complementarias implican que para cada sexo hay un espacio donde las cualidades naturales que poseen se desarrollarán mejor, más eficazmente para la sociedad. El público pertenece a los varones y el privado a las mujeres.

\section{LA DIMENSIÓN POLÍTICA DEL AMOR.}

El amor configura prácticas sociales e individuales, es parte intrínseca del proceso de construcción de las relaciones de género y reflejo de las mismas. Tiene para las mujeres una especial connotación, ya que, siguiendo a Lagarde (2005), las mujeres están socializadas en el amor (los varones lo están en el poder) y en el darse al otro. "Para las mujeres, el amor no es sólo una experiencia posible, es la experiencia que nos define. ... Las mujeres hemos sido configuradas socialmente para el amor, hemos sido construidas por una cultura que coloca al amor en el centro de nuestra identidad" (Lagarde, 2005:347).

Firestone (1976) establecía ya en los setenta que "las mujeres y el amor son pilares básicos. Analizadlos y estaréis amenazando la estructura misma de la cultura". Al intentar analizar los mecanismos que reproducen la desigualdad, incluso $-\mathrm{y}$ especialmente- en sociedades formalmente igualitarias, el feminismo ha encontrado en el amor una clave fundamental. Jónnasdóttir (1993:315) sostiene que "la mujer necesita amar y ser amada para habilitarse socio-existencialmente, para ser una persona. Pero (...) carece de autoridad para determinar las condiciones del amor en la sociedad y cómo deben ser sus productos". Es decir, se producen y reproducen relaciones jerárquicas, desiguales, de poder.

Sobre el cómo se producen esas relaciones de poder, la literatura feminista ha puesto el acento en la violencia patriarcal. Sin descuidar este aspecto, este análisis 
enfatiza el amor dado y recibido voluntariamente, sin coacción, que como hemos visto es intrínseco a la feminidad normativa. Siguiendo a Jónnasdóttir (1993:274) “... no puede tomarse la coerción o la violencia directa y abierta como el mecanismo vital de la estructura autoritaria sexual que predomina en las sociedades contemporáneas formalmente libres e igualitarias". Así, la gran aportación de Jónnasdóttir es poner en primer plano al amor dado y entregado libremente y establecerlo como base para que el patriarcado o sistema sexo-género, siga impidiendo a las mujeres ser sujetos plenos y ejercitar sus derechos formales.

“... creo que hay que centrarse en el amor dado -y recibido- libremente (...). Son las experiencias extáticas y de cuidados "libremente contratadas" en las relaciones de amor íntimas, y el "libre intercambio" de lo socioexistencial, es decir, la confirmación personal y genérica, en el trabajo y en otros contextos públicos, lo que ahora es "central para las realidades sociales que se reflejan en nuestro uso del término individual y en parte están constituidas por él". En estas relaciones "libres" sobre transacciones de poder existencial, poder que crea y recrea la identidad individual y la fuerza de actuación, es donde los hombres tienden a explotar a las mujeres. Y las mujeres nos dejamos explotar porque amamos; esto es, no sólo "en nombre del amor" (...). Sabemos que estamos haciendo el bien a otros y eso nos hace bien a nosotras" (1993:274).

De este modo, el amor es concebido como «poder humano alienable y con potencia causal, cuya organización social es la base del patriarcado contemporáneo» (1993:311). Además constituye un elemento clave en el desarrollo del capitalismo moderno. El amor romántico refuerza las posiciones de subordinación de las mujeres, trascendiendo de las relaciones personales/sociales para adquirir una dimensión política-económica, en tanto en cuanto, proporciona el gratuito sostenimiento del sistema a través de los cuidados gratuitos Jónnasdóttir (1993: 322) analiza que existe una relación cada vez más dependiente del sistema capitalista del poder recreativo reproductivo-, y por tanto más dependiente de "condicionar a la gente para usar e invertir su energía para servir directa o indirectamente, al crecimiento económico continuado". El análisis de la economía desde la perspectiva de género aporta datos reveladores sobre la configuración del Estado de Bienestar basado en la gratuidad de los cuidados (asumidos por las mujeres) y en todo un sistema fiscal y tributario que mantiene la estructura patriarcal del varón proveedor/mujer dependiente; limitando a las mujeres el acceso a los recursos en iguales condiciones que los varones.

Los conceptos que hemos analizado a través del discurso Rousseauniano, como fundador del patriarcado moderno, y de la doctrina vaticana, redundan en la noción de amor romántico que está presente en las sociedades contemporáneas. La complementariedad de los sexos es un elemento clave que desembocará en la familia nuclear como adalid. Así como la esencia femenina que predispondría a las mujeres a la renuncia personal y la entrega al otro por su potencialidad para convertirse en 
madres, lo hagan o no. De este modo, el amor romántico sirve como transmisor de los valores patriarcales (esencialismo femenino, complementariedad y división sexual del trabajo) que in fine dificultan o limitan de facto a las mujeres el ejercicio de su ciudadanía.

\section{SUJETO POLITICO Y CIUDADANIA.}

La dimensión política que adquiere el amor es una forma más de mostrar cómo la feminidad normativa impregna la construcción de un sujeto mujer, y por tanto del sujeto político mujer que redundará en un déficit en el ejercicio de la ciudadanía (cuando no en su titularidad).

Con ciudadanía deficitaria o déficit de ciudadanía se entiende que a pesar de la igual consideración legal, ejercer la ciudadanía requiere de condiciones de vida en sentido material, educativo y psicológico, para las que todavía hoy las mujeres encuentran más dificultad, tal como expresa $\mathrm{M}^{\mathrm{a}}$ Teresa Gallego, de modo que para muchas, seguramente millones de mujeres, la ciudadanía jurídica puede no ser más que un cascarón vacío (Villota, 1998: 88). Y el género es un factor de carácter estructural que determina esta situación. Así, cualquier redefinición de la ciudadanía no puede ignorar una construcción normativa de lo femenino que restringe los derechos civiles, políticos y sociales de la mitad de la población (Rosa Cobo, 2002).

En términos generales, cuando la Ciencia Política ha abordado la ciudadanía de las mujeres, no ha incidido en la raíz, en la base del impedimento de su ejercicio, incluso de su titularidad, esto es, el sesgo androcéntrico de individuo sobre el que se asienta el propio concepto de ciudadanía. Ya hemos mencionado la negación de la individualidad a las mujeres como eje de esta carencia. También se ha hecho alusión a que este proceso se acompaña de la heterodesignación.

Todo ello se traduce, a efectos prácticos, en que el sujeto mujer se intercambia por el de madre. Por lo que aunque no se sea madre, ni se piense serlo, el sistema te tratará como si lo fueras, o como si lo fueras a $\operatorname{ser}^{16}$. Jónnasdóttir (1993: 285) apunta un argumento interesante:

“...desde los albores del patriarcado, hasta su cambio a la forma libre e igual predominante, se ha excluido a las mujeres de una posición igual a la masculina, no en un aspecto particular [la maternidad], sino como tales. Además, las condiciones sociales de muchas mujeres competentes, sin obstáculos laborales y con capacidad de

\footnotetext{
${ }^{16}$ Como hemos visto, "sea o no puesta acto, constituye su destino".
} 
elección, incluso desde el denominado adelanto de la democracia, indican que todavía, lo que anda mal en ellas es que son mujeres", no que sean madres.

Este intercambio del sujeto mujeres por el de "madres" puede analizarse de forma más explícita que en otros ámbitos de intervención, a través del enfoque que adoptan las legislaciones/políticas sociales de los Estados del Bienestar occidentales a partir de la II Guerra Mundial. Los derechos de las mujeres, podría decirse, derivan de su maternidad, no de su individualidad. Elisabeth Wolgast (Villota, 1998:233) llega incluso a hablar de "falsos derechos" y pone como ejemplo las leyes de protección de la maternidad, que permiten a las mujeres, en tanto que embarazadas, trabajar menos y en condiciones menos penosas que los varones, y que lo que estarían protegiendo en realidad no son los derechos de las mujeres, sino al futuro bebé, cuyos derechos suelen primar sobre los de éstas. Estas legislaciones no sólo no implican autonomía para las mujeres, sino que refuerzan la subordinación en el rol de madre y esposa.

El proceso de individualización de los derechos todavía es deficiente. Especialmente en los relacionados con la fiscalidad y la seguridad social, cuyo sesgo patriarcal hace que todavía se conciban desde la óptica del varón proveedor-mujer dependiente/cuidadora y estén impregnados de un concepto de familia patriarcal. Lo vemos por ejemplo en los muy diferentes permisos de maternidad y paternidad, o en cómo el IRPF actual penaliza el trabajo asalariado de las mujeres trabajadoras.

Incluso en las legislaciones actuales los argumentos en pro de la igualdad siguen a menudo impregnados de esta feminidad normativa. El ejemplo quizás más evidente es el de las políticas de conciliación, que han tenido gran protagonismo en las recientes campañas institucionales (y su correspondiente presupuesto ${ }^{17}$ ), y que han sido enfocadas como un asunto de mujeres y dirigidas hacia ellas como únicas responsables de los cuidados. Es cierto que tímidamente se ha mencionado la corresponsabilidad, pero todavía más a nivel discursivo que práctico.

Es a lo que se refiere Jónnasdóttir (1993:254) cuando dice que existen contradicciones inherentes en la formulación de las políticas públicas sociales, de igualdad o sea cual fuere su clasificación técnica: "si contemplamos los argumentos en pro de la igualdad que aparecen actualmente en los documentos políticos públicos, creo que los de tipo más habitual todavía implican un planteamiento utilitario de las mujeres" (1993: 267). Pero no sólo en los argumentos relacionados directamente con

${ }^{17}$ Quiero incidir en que con esto no sólo hay un error metodológico que impedirá el objetivo estratégico de la igualdad efectiva, sino que se desperdician o mal invierten recursos públicos. Hecho que además redundará en la percepción negativa que la sociedad, en términos generales, tiene sobre que se inviertan recursos públicos en algo que consideran innecesario, al ostentar la igualdad formal. 
la igualdad, la feminidad normativa subyace a todo el entramado legal y de desarrollo de políticas.

Así, retomando el origen de la cuestión, para evitar este déficit de ciudadanía hay que atender al concepto de individuo sobre el que se asienta la ciudadanía y permite un sujeto político pleno, y que la feminidad normativa niega a las mujeres. Tiene razón Pateman (1995) cuando afirma que es un concepto patriarcal, pero eso no invalida su potencial alcance. Frente al individuo patriarcal, propone basarse en una concepción que reconozca de las diferencias sexuales. Da a entender que la humanidad tiene dos cuerpos diferenciados y que las mujeres deben acceder a la ciudadanía y a la democracia como mujeres, es decir, deben incorporarse en tanto que individuos concretos dotados de una capacidad diferente -la maternidad- y no como individuos abstractos.

Considero que debe darse una significación política al trabajo reproductivo, pero como una necesidad social $-\mathrm{y}$ por tanto socialmente compartida $^{18}$ - para el sostenimiento de un Estado (del Bienestar). No como especificidad de las mujeres. Si no, el intercambio del sujeto mujer por el de madre, seguirá inamovible.

Entonces, ¿cómo ha de tratarse la diferencia? ¿o no debe tratarse? Cuestionar la manera en el concepto de diferencia opera en la construcción de un sujeto político, tanto individual como colectivo, no implica de ninguna manera que se pretendan anular las diferencias y modelar una especie de ciudadanía "neutra", ni relaciones sociales neutrales desde el punto de vista genérico, ni de abogar por la desaparición de la diferencia sexual como distinción pertinente, en términos de Mouffe (1993:8). No se trata de eso. Las diferencias existen pero no debe basarse en ellas la conceptualización de la ciudadanía (ni de ninguna otra cosa). La utilidad de "diferencia" como concepto tiene un alcance limitado.

Como Jónnasdóttir "no comparto la creencia...de que esta categoría es la máxima depositaria de las clarificaciones conceptuales" (1993:276). No es en la diferencia en sí sino en las relaciones estructurales entre los sexos en lo que hay que poner atención para intentar explicar las diferentes posiciones de poder de mujeres y hombres (1993:277). No quiere esto decir que este concepto no sea importante desde el punto de vista teórico y empírico, pero no debe convertirse en un paradigma político, como apunta Cirillo (2002).

\footnotetext{
${ }^{18}$ Incluyendo como elemento clave el papel activo del Estado en medios y recursos.
} 
Estos planteamientos se reflejan en la construcción de un sujeto político mujer diferente según se aborde desde la igualdad o desde la diferencia. Y la forma en que se plantea el sujeto repercute a su vez en la posibilidad del sujeto político mujeres, en plural, en el empeño de seguir planteando no sólo la posibilidad, sino la necesidad, de estructurar un sujeto político feminista capaz de abordar las muy diversas y desiguales vindicaciones del siglo XXI.

El género en el que se enmarca la demanda de un sujeto político con capacidad de intervención social y de negociación política es el de la vindicación. La exigencia de que los derechos civiles, sociales y políticos no sólo se apliquen sino que puedan ser ejercidos por las mujeres en el mismo grado que los varones, esto es, el uso paritario de todas las instancias de poder, allí donde se toman decisiones ${ }^{19}$. Sin embargo, "el núcleo del planteamiento de la diferencia sexual es el rechazo de la vindicación, pues, como afirma Irigaray, hay que poner de manifiesto la singularidad sexual de las mujeres y su necesidad de articular un "singular propio" (Cobo, 2002).

La forma de ejercer la ciudadanía no es sólo individual, también es colectiva. De hecho se retroalimentan. Según $\mathrm{M}^{\mathrm{a}}$ Teresa Gallego "es necesario poner en práctica diversas estrategias que den lugar a recursos de poder para las mujeres, en el sentido de que cada vez más mujeres individualmente logren autonomía y capacidad de decisión (agency), pero también como grupo puedan influir o decidir medidas favorables a todas las mujeres" (Villota, 1998:90).

Esta forma de ejercer la ciudadanía colectiva requiere de un nosotras, como explica Valcárcel (Cobo, 2002:42), que es requisito a su vez de la construcción de la individualidad. Pero definir una categoría mujeres presenta controversias. Siguiendo la idea de Lidia Cirillo, "ningún grupo puede unir a sus miembros en una relación de solidaridad, ser consciente de la naturaleza de sus necesidades y moverse en una dirección y no en otra, si no es capaz de expresar de alguna forma quién es" (Cobo, 2002:42). Pero las mujeres no constituyen una cultura. La cuestión será determinar, como se pregunta Scott, si existe un interés de las mujeres que atraviese las barreras de clase, etnicidad y raza, y que permita construir un nosotras, un sujeto político colectivo, feminista. Y si así fuera, ¿en qué consiste?

Todo colectivo que aspira a convertirse en un actor social debe construirse una identidad política. "El feminismo de la tradición igualitaria considera la construcción

\footnotetext{
${ }^{19}$ Presencia e influencia no sólo en el poder político, también en el económico-empresarial, y “al lado de ellos, deben colocarse sistemáticamente los medios, la religión, la creatividad y el saber". Como advierte Amelia Valcárcel (2008:169) "son, nada menos que las fases performativas y legitimadoras de los otros dos poderes, más ejecutivos".
} 
de una identidad feminista como la condición de posibilidad para que las mujeres se constituyan en sujetos y para articular colectivamente la lucha política". Esta identidad, lejos de basarse en esencias u ontologías, como señala Amorós, debe ser crítico-reflexiva respecto a la identidad femenina:

"El fundamento en la construcción de una identidad feminista es que todas las mujeres comparten inicialmente una situación de discriminación. La identidad debe ser entendida instrumentalmente como el fundamento de la lucha contra la opresión, pero nunca como el enquistamiento en la diferencia o la exaltación de una esencia. Sin identidad colectiva no hay movimiento social, ni posibilidades de combatir la infrarrepresentación política ni económica, ni un discurso ideológico con posibilidades de ganar una hegemonía política" (2005:41).

Para formular adecuadamente el proyecto debe descartarse la idea esencialista de buscar una identidad de mujeres como mujeres. Sino más bien "como la persecución de las metas y aspiraciones feministas dentro del contexto de una más amplia articulación de demandas. Esas metas y aspiraciones podrían consistir en la transformación de todos los discursos, prácticas y relaciones sociales donde la categoría "mujer" está construida de manera que implica subordinación" (Mouffe, 1992:11).

Así, a pesar de las dificultades que pueda suponer su definición, se configura como la mejor manera en la que poder intervenir en la conquista de espacios de poder a nivel fáctico, pero sobre todo a nivel simbólico, con el objetivo puesto en la paridad.

El fin de la paridad es un cambio de actitudes y valores respecto a la distribución social de los sexos. Y esto, requiere auctoritas. Si todo un colectivo carece de autoridad, su poder no es legítimo, es superfluo. La desautorización de las mujeres ha sido y es necesaria para el mantenimiento del patriarcado.

Amelia Valcárcel analiza que "el espacio de visibilidad disponible ocupado por representaciones estereotipadas o decidida y buscadamente misóginas reduce la capacidad de conocimiento y, por ende de reconocimiento. Por este medio se disuade mejor y con mayor prontitud" (2008:182). "El reconocimiento es público ... Supone autoridad, prestigio, respeto" (2008:185). Valcárcel concede especial importancia a esta imagen completa de las mujeres como género. ¿Cuál es su imagen colectiva? La que los medios y la publicidad proporcionan: edad intemporal antes de la adultez plena, deber de agrado... esto es, poder sabiamente escondido; o bien víctimas, de abusos, violencia, tráfico... poder inexistente" (2008:172). Y se pregunta "Si todo un colectivo carece de autoridad, ¿qué representa eso en su modo de detentar el poder que consiga o mantenga?" (2008:171). 
Amorós incide en la importancia del grupo juramentado (2005:454 y ss) para acceder al poder. "Las mujeres como "espacio de la idénticas" no hemos tenido históricamente esta estructuración juramentada, sino ... disposición "en serie" o atomizada, dispersión en el espacio privado que condena a la impotencia al colectivo como tal". Tendiendo todo esto en cuenta, "la igualdad con los varones en el espacio de la política implica para las mujeres la sororidad -como constructo juramentado-, en la medida misma en que esta sororidad implica el homologarse con los varones, ya que sólo accede al poder el grupo juramentado" (2005:203). Así, la construcción de un sujeto político feminista ha encontrado la fórmula más eficaz y adecuada en los pactos entre mujeres, en términos de Amorós. Que tienen, explica, sus precedentes en la lucha sufragista, y que se concretan en políticas de redes y que

"constituyen para el feminismo un medio para el logro de sus objetivos de acceso de las mujeres al espacio público y a la igualdad. Pero al mismo tiempo, son un fin en sí por el valor intrínseco que para el movimiento feminista tiene la construcción del movimiento de mujeres como sujeto político".

\section{BIBLIOGRAFÍA.}

ALFARO, J. (2005): "La retórica del poder. Miradas respecto del feminismo, las mujeres y lo social. Análisis del discurso de la Iglesia Católica". Athenea Digital, Número 7.

ÁLVAREZ CONDE, Enrique et al (2009): Estudios Interdisciplinares sobre Igualdad. Iustel, Madrid.

AMORÓS, C. (1997): Tiempo de feminismo. Sobre feminismo, proyecto ilustrado y postmodernidad, Madrid, Cátedra.

AMORÓS, C. (2005): La gran diferencia y sus pequeñas consecuencias... para las mujeres. Madrid, Cátedra.

ARMSTRONG, N. (1991): Deseo y ficción doméstica, Madrid, Cátedra.

BETETA, Yolanda (2009): Las heroínas regrasan a Ítaca. La construcción de las identidades femeninas a través de la subversión de los mitos. Investigaciones Feministas, vol 0, 163-182.

BOURDIEU, P. (2000): La dominación masculina, Barcelona, Anagrama.

BOURDIEU, P. (2000): Poder, derecho y clases sociales, Bilbao, Palimpsesto

BOURDIEU, P. (2000): Intelectuales, política y poder, Buenos Aires, Eudeba.

CIRILLO, L. (2002): Mejor huérfana: por una crítica feminista al pensamiento de la diferencia. Madrid, Antrophos.

COBO, R. (1992), Democracia y patriarcado en Jean-Jacques Rousseau. Tesis Doctoral

UCM. URL Oficial: http://eprints.ucm.es/tesis/19911996/S/1/S1005501.pdf

COBO, R. (1995): Fundamentos del patriarcado moderno. Jean Jacques Rousseau, Cátedra, Madrid 
COBO, R. (2002): "Democracia paritaria y sujeto político feminista" $\mathrm{n}^{\mathrm{o}} 36$, Anales de la Cátedra Francisco Suárez, (Ejemplar dedicado a: El derecho de una democracia cosmopolita), p. 29-44.

ESTEBAN, M. L. y TÁVORA, A. (2008): “El amor romántico y la subordinación social de las mujeres: revisiones y propuestas". Anuario de Psicología vol. 39, $\mathrm{n}^{\circ} 1$. Universidad de Barcelona.

FIRESTONE, S. (1976): La dialéctica del sexo, Barcelona, Kairós.

FOUCAULT, M. (2000): Estrategias de poder, Obras esenciales, Vol. II, Barcelona, Paidós.

FOUCAULT, M. (1992) : Microfisica del poder, Madrid, Ediciones La Piqueta

JÓNNASDÓTTIR, A (1993): El poder del amor. ¿Le importa el sexo a la democracia? Madrid, Cátedra.

LAGARDE, M. (2005): Para mis socias de la vida, Madrid, Horas y Horas.

LIPOVETSKY, G. (1987): La era del vacio. Ensayos sobre el individualismo contemporáneo, Barcelona Anagrama.

MARTÍN-BARÓ, I. (1989): Sistema, grupo y poder, El Salvador, UCA Editores.

MILLET, K. (2010): Política sexual, Madrid, Cátedra.

MIYARES, A. (2003): Democracia feminista, Madrid, Cátedra.

MOUFFE, C. (1993): "Feminismo, ciudadanía y política democrática radical", Debate feminista, núm. 7.

PATEMAN, C. (1995): El contrato sexual, Barcelona, Anthropos.

ROUSSEAU, Jean-Jacques (1997): Emilio, o de la educación, Madrid. Alianza Editorial.

VALCÁRCEL, A. (1991): Sexo y Filosofía, Barcelona, Anthropos.

VALCÁRCEL, A. (1997): La política de las mujeres. Madrid, Cátedra.

VALCÁRCEL, A. (2008): Feminismo en el mundo global. Madrid, Cátedra.

VALCÁRCEL, A. (2001): La memoria colectiva y los retos del feminismo. Serie Mujer y Desarrollo. N $\mathrm{N}^{\mathrm{o}}$ 31, CEPAL (NNUU).

VANDER ZANDEN, J. W. (1995): Manual de psicología social. Barcelona, Paidós Básica.

VILLOTA, Paloma (ed.) (1998): Las mujeres y la ciudadanía en el umbral del siglo XXI, Madrid, Editorial Complutense.

\section{DOCUMENTOS VATICANOS:}

\section{Doctrina Social de la Iglesia}

1988. Carta Apostólica Mulieris Dignitatem del Sumo Pontífice Juan Pablo II Sobre la dignidad y la vocación de la mujer con ocasión del Año Mariano

Carta del Papa Juan Pablo II a las Mujeres, 1995.

Carta a los Obispos de la Iglesia Católica sobre la colaboración del Hombre y la Mujer en la Iglesia y el mundo. Congregación Para la Doctrina de la Fe. Documento de carácter doctrinal, 31 de julio de 2004

Agencia Fides. Congregación para la Evangelización del Pueblo. Dossier FIDES “ $L a$ figura de la mujer en la vida de la Iglesia". Ciudad del Vaticano. 12 de agosto de 2008. 